УДК 616.858-008.6:612.114:616.092.4:616-01/-099:57.084.1

Для цитирования: Жанаева С.Я., Альперина Е.Л., Геворгян М.М., Дземидович С.С., Идова Г.В. В-клетки периферической крови при болезни Паркинсона. Клинические и экспериментальные данные. Сибирский вестник психиатрии и наркологии. 2020; 3 (108): 11-16. https://doi.org/10.26617/1810-3111-2020-3(108)-11-16

\title{
В-клетки периферической крови при болезни Паркинсона. Клинические и экспериментальные данные
}

\section{Жанаева С.Я., Альперина Е.Л., Геворгян М.М., Дземидович С.С., Идова Г.В.}

Научно-исследовательский институт физиологии и фундаментальной медищинь

Россия, 630117, Новосибирск, ул. Тимакова, 4

\section{PEЗЮME}

Ключевую роль в патогенезе болезни Паркинсона (БП) играет хроническое воспаление, сопровождающееся изменением субпопуляционного состава периферических иммунокомпетентных клеток, среди которых всё большее внимание привлекают $\mathrm{CD} 19^{+}$В-клетки, включенные в адаптивные реакции иммунной системы, а также в патогенез многих заболеваний ЦНС. Однако данные о них противоречивы и малочисленны. Целью исследования являлось выявление особенностей содержания В-клеток и их субпопуляции $\mathrm{CD} 19^{+} \mathrm{CD} 25^{+}$регуляторных В-клеток (B-regs) в периферической крови у пациентов с БП и у трансгенных мышей линии А53Т с $\alpha$-синуклеопатией. Верификация идиопатической формы и стадии БП проводилась в соответствии с международными клинико-диагностическими критериями Банка головного мозга общества БП Великобритании и согласно модифицированной шкале стадий заболевания Хен и Яра. В качестве экспериментальной модели БП служили мыши линии А53Т с гиперэкспрессией мутантной формы человеческого $\alpha$-синуклеина, контролем к ним - мыши дикого типа (WT). Определение В-лимфоцитов и B-regs проводилось методом проточной цитофлуориметрии с использованием меченых моноклональных антител. Показано, что содержание CD19+ Bклеток в периферической крови у пациентов общей группы (мужчины и женщины) с БП не отличалось от их уровня у здоровых лиц, однако у женщин В-клеток было больше, чем у мужчин. Содержание CD19+CD25+ $\mathrm{B}$ regs у пациентов общей группы существенно повышалось по сравнению со здоровыми лицами и зависело от стадии заболевания, при этом наиболее значимое увеличение обнаружено на III стадии заболевания. У 10 месячных мышей линии A53T с признаками БП число CD19+ B-клеток, а также CD19+CD25+ B-regs в периферической крови совпадало с уровнем контроля. Таким образом, нами показано, что на фоне неизмененного уровня В-клеток у пациентов с БП при прогрессировании заболевания нарастает содержание субпопуляции B-regs. Предполагается, что B-regs, продуцирующие антивоспалительные цитокины, включаются в нейропротективные механизмы при развитии БП.

Ключевые слова: болезнь Паркинсона, мыши линии А53Т с $\alpha$-синуклеинопатией, В-клетки, регуляторные В-клетки, периферическая кровь.

\section{ВВЕДЕНИЕ}

Болезнь Паркинсона (БП) - нейродегенеративное заболевание, основными признаками которого являются прогрессирующая гибель дофаминергических (DA) нейронов, появление телец Леви, содержащих агрегаты $\alpha$-синуклеина, и хроническое нейровоспаление $[1,2,3,4,5]$. Наряду с активацией микроглии и повышенной лимфоцитарной инфильтрацией в центральной нервной системе (ЦНС), воспаление при БП сопровождается изменением состава и фенотипа периферических иммунных клеток [4, 5, 6, 7]. Существующие данные указывают, главным образом, на ключевую роль в патогенезе БП периферических Тклеток и их субпопуляций $[4,5,6,7]$. Вместе с тем всё большее внимание в последнее время привлекают В-клетки, которые являются важными компонентами адаптивной иммунной системы и включены в патогенез многих заболеваний ЦНС
[8]. Однако данные об изменениях В-клеток при БП противоречивы. Одними авторами показано, что процентное содержание В-клеток снижается и связано со шкалой тяжести заболевания UPRSD $[5,6]$, другие не обнаружили такой зависимости [7]. При этом существуют лишь единичные работы о содержании и функции $\mathrm{CD} 19^{+} \mathrm{CD} 25^{+}$регуляторных В-клеток (B-regs) у пациентов с БП [9]. В то же время B-regs рассматриваются как новая популяция клеток, участвующая в воспалительных и аутоиммунных процессах $[10,11,12,13$, 14], которые могут быть включены в патогенетические механизмы нейродегенеративных заболеваний, включая и БП. Клинические данные подтверждаются результатами, полученными в экспериментальных моделях, среди которых трансгенные мыши А53Т, экспрессирующие мутантный ген $\alpha$-синуклеина, наиболее полно воспроизводят основные звенья патогенеза БП $[15,16]$. 


\section{ЦЕЛЬ ИССЛЕДОВАНИЯ}

В связи с вышесказанным целью исследования являлось выявление особенностей содержания Вклеток и B-regs в периферической крови у пациентов с БП и у трансгенных мышей линии А53Т с $\alpha$-синуклеопатией.

\section{МАТЕРИАЛЫ И МЕТОДЫ}

\section{Клиническое исследование}

В исследовании приняли участие 19 пациентов (13 женщин и 6 мужчин) с БП, проходивших лечение в А1 Клинике НИИФФМ (г. Новосибирск). Средний возраст в группе пациентов с БП соста-

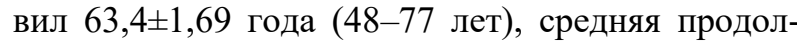
жительность заболевания - 6,1 $\pm 0,6$ года (2-16 лет). В группу больных были включены пациенты co II (32\%) и III (68\%) стадиями заболевания. В качестве контроля были вовлечены 11 практически здоровых лиц (7 женщин и 4 мужчины) близкого возраста - в среднем 59,6 $\pm 1,63$ года (5168 лет).

Верификация диагноза идиопатической БП, её формы и стадии проводилась в соответствии с международными клинико-диагностическими критериями Банка головного мозга общества БП Великобритании (UK Parkinson's Disease Society Brain Bank) и согласно модифицированной шкале стадий заболевания Хен и Яра (Modified Hoehn and Yahr Scale). Все участники подписали информированное добровольное согласие на участие в исследовании.

Кровь у пациентов и здоровых лиц забирали в утренние часы из локтевой вены в пробирки BD Vacutainer CPT, содержащие антикоагулянт и разделительную систему гель/Ficoll ${ }^{\mathrm{TM}}$, затем инкубировали при комнатной температуре в течение 1 часа и центрифугировали при $1800 \mathrm{~g} \mathrm{в}$ течение 20 минут. Суспензию мононуклеарных клеток (МНК) готовили согласно общепринятым протоколам. Определение В-лимфоцитов и B-regs проводилось методом поэтапного гейтирования с использованием моноклональных античеловеческих антител, конъюгированных с флюорохромами (BD Pharmingen ${ }^{\mathrm{TM}}$, USA): для CD19 - fluorescein isothiocynate (FITC), для CD25 - phycoerythrin (PE). Для окрашивания клеток 25 мкл суспензии МНК культивировали со смесью антител (по 1,5 мкл каждого антитела) в течение 15 минут в защищенном от света месте. После окрашивания лизировали эритроциты в BD FASC Lysing Solution (Becton Dickinson, USA) в течение 10 минут, клетки однократно отмывали в растворе PBS, осадок ресуспендировали в 100 мкл PBS. Анализ образцов проводили на проточном лазерном цитофлуориметре FACSCalibur (Becton Dickinson, USA). В каждом образце анализировали не менее 50000 клеток. Полученные результаты обрабатывали в программе CellQuest Pro.
Экспериментальное исследование

В работе использовались мыши-самцы линий B6.CG-Tg (Prnp-SNCA*A53T) 23MKle/J (A53T) с гиперэкспрессией мутантной формы человеческого $\alpha$-синуклеина и C57BL/6J (WT, дикий тип) $(\mathrm{n}=11$ в каждой группе) в возрасте 9,5-10,0 месяца. Животных получали из SPF-вивария Института цитологии и генетики СО РАН (г. Новосибирск) и содержали по 5 особей в клетке (40х25x15 см) в стандартных условиях вивария со свободным доступом к пище и воде.

Кровь у мышей забирали после их мгновенной декапитации в пробирки, содержащие K3EDTA (Becton Dickinson, USA). Определение в периферической крови содержания $\mathrm{CD} 19^{+}$В-лимфоцитов и CD $19^{+} \mathrm{CD} 25^{+}$B-regs также проводилось методом проточной лазерной цитофлуориметрии, подобно описанному выше у человека, но с использованием меченых антимышиных моноклональных антител производства BD Pharmingen ${ }^{\mathrm{TM}}$ (USA) к поверхностным маркерам клеток: CD19 (FITC) и CD25 (Brilliant Violet 421).

Полученные данные анализировали с помощью статистических программ SPSS (версия 23.0) и Statistica 10. Характер распределения исследуемых параметров оценивали с использованием критериев Колмогорова-Смирнова и Шапиро-Уилка. В клинической части исследования для оценки возможных влияний факторов группы (БПБ, здоровые лица), пола, возраста, стадии и продолжительности заболевания на состав лейкоцитов в периферической крови проводили множественный регрессионный анализ. Дальнейшую оценку межгрупповых различий осуществляли с помощью дисперсионного анализа ANOVA, попарное сравнение проводили с применением теста Fisher LSD.

У экспериментальных животных при нормальном распределении показателей достоверность различий в группах оценивали по критерию Стьюдента (t). Данные определяли с учетом стандартной ошибки среднего арифметического $(\mathrm{M} \pm \mathrm{m})$. Выявленные различия считали статистически значимыми при величине $\mathrm{p}<0,05$.

\section{РЕЗУЛЬТАТЫ И ОБСУЖДЕНИЕ}

Результаты множественного регрессионного анализа обнаружили, что для показателя содержания CD19+ В-лимфоцитов фактор группы был статистически незначим $(\mathrm{F}(1,24)=0,12, \mathrm{p}=0,736)$. Последующий Post hoc analysis не выявил статистически значимых различий по количеству Влимфоцитов между пациентами с БП и здоровыми лицами $(7,2 \pm 0,56$ против $6,9 \pm 0,59, \mathrm{p}>0,05)$.

Фактор пола оказывал значимое влияние на содержание $\mathrm{CD} 19^{+}$В-лимфоцитов в периферической крови $(\mathrm{F}(1,22)=6,09, \mathrm{p}=0,021)$, но только во взаимодействии с фактором группы. Так, у паци- 
ентов с БП содержание В-клеток среди женщин было выше, чем у мужчин $(\mathrm{p}<0,05)$, тогда как здоровые мужчины и женщины не различались по содержанию В-лимфоцитов (табл. 1). Т.е. сам по себе фактор пола не оказывал влияние на содержание В-клеток.

Т а б л и ц а 1. Содержание B-лимфоцитов и B-regs в периферической крови у здоровых лиц и пациентов с БП в зависимости от пола $(\mathrm{M} \pm \mathrm{m})$

\begin{tabular}{|c|c|c|}
\hline Популяции клеток; группа & Здоровые лица - контроль (n) & Пациенты с БП (n) \\
\hline CD19+ В-лимфоциты, \% & & $7,2 \pm 0,56(16)$ \\
- Общая группа & $6,9 \pm 0,59(10)$ & $8,1 \pm 0,71(10) \#$ \\
Ж Женщины & $6,4 \pm 0,69(7)$ & $5,7 \pm 0,53(6)$ \\
\hline Мужчины & $8,1 \pm 0,71(3)$ & \\
\hline CD19+CD25+ B-regs, \% от B- клеток & & $4,7 \pm 0,72(16)^{* *}$ \\
- $\quad$ Общая группа & $1,3 \pm 0,34(8)$ & $4,9 \pm 1,13(10)^{*}$ \\
Женщины & $1,0 \pm 0,23(5)$ & $4,5 \pm 0,96(6)^{\&}$ \\
\hline
\end{tabular}

П р и м е ч а н и е. Уровень достоверности: ${ }^{*}-\mathrm{p}<0,05, * *-p<0,001,{ }^{\&}-\mathrm{p}=0,09$ по сравнению с соответствующей группой здоровых лиц; \# - p<0,05 по сравнению с группой мужчин.

Другими авторами также были продемонстрированы различия относительно уровня В-клеток в группах здоровых лиц и пациентов с БП, при этом как больные, так и здоровые женщины отличались более высоким процентным содержанием В-клеток, чем мужчины [6]. Наряду с этим установлена зависимость процентного количества Вклеток от показателей шкалы UPDRS, которое было ниже при более высоких показателях шкалы, что давало основание говорить о негативной корреляции с тяжестью заболевания и сделать заключение о содержании В-клеток как о предикторе прогрессирования БП [6].

Что касается данных о зависимости содержания В-клеток от стадии заболевания, то влияние этого фактора проявлялось во взаимодействии с фактором пола $(\mathrm{F}(2,20)=3,59, \mathrm{p}=0,046)$, тогда как фактор стадии заболевания на уровень клеток не влиял. У женщин со II стадией БП содержание
В-лимфоцитов было в 1,5 раза выше по сравнению с таковым числом у здоровых женщин $(9,7 \pm 1,04$ против $6,4 \pm 0,68, \mathrm{p}<0,001)$.

Известно, что В-клетки являются важными компонентами адаптивной иммунной системы и, помимо выработки антител, могут выполнять другие функции, включая презентацию антигена Т-клеткам и выработку про- и противовоспалительных цитокинов. Опубликованные в последние годы данные свидетельствуют, что В-клетки включают субпопуляцию B-regs, обладающих иммунорегуляторной функцией, связанной с их способностью продуцировать противовоспалительные цитокины ИЛ-10, ИЛ-35 и TGF- $\beta$, которые, в свою очередь, оказывают влияние на Тregs, Т-хелперы (Тх)1 и Тх17 на разных стадиях развития воспалительной реакции $[11,12,13]$. Предполагается, что B-regs могут вносить вклад в патогенез БП $[8,9]$.

T а б л и ц а 2. Содержание B-regs в периферической крови у пациентов с II и III стадиями БП (M \pm m)

\begin{tabular}{|c|c|}
\hline $\begin{array}{c}\text { Популяции клеток; } \\
\text { группа/стадия }\end{array}$ & Содержание клеток, \% (n) \\
\hline 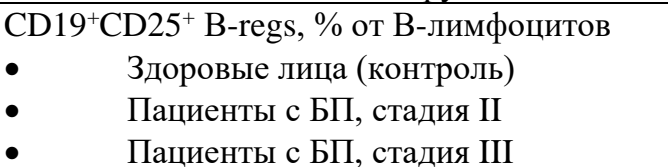 & $\begin{array}{c}1,3 \pm 0,34 \%(8) \\
4,1 \pm 1,09 \%(5) \\
4,9 \pm 0,74 \%(11)^{*}\end{array}$ \\
\hline
\end{tabular}

П р и м е ч а н и е. Уровень достоверности: * - p<0,001 по сравнению со здоровыми лицами

Полученные нами результаты множественного регрессионного анализа выявили значимое влияние фактора группы (здоровые, БП) на содержание $\mathrm{CD} 19^{+} \mathrm{CD} 25^{+}$B-regs в периферической крови $(\mathrm{F}(1,22)=10,22, \mathrm{p}=0,004)$, которое у больных БП более чем в 3 раза превышало таковое количество в группе здоровых лиц (табл. 1). Было обнаружено, что только у женщин повышалось содержание B-regs по сравнению с группой здоровых лиц $(\mathrm{p}<0,001)$, тогда как мужчин прослеживалась лишь тенденция к их повышению $(\mathrm{p}=0,09)$ (табл. 1). В то же время фактор стадии заболевания оказывал значимое влияние на содержание B-regs $(\mathrm{F}(2,21)=5,19, \mathrm{p}=0,014)$. Статистически значимые различия в содержании B-regs со здоровыми лицами (контроль) выявлены у пациентов с III стадией БП ( $<<0,01$, табл. 2). Факторы возраста и продолжительности заболевания не влияли на показатели В-клеток и B-regs ни самостоятельно, ни во взаимодействии с фактором группы. 
Анализ содержания CD19+ B-клеток в периферической крови у 10-месячных мышей линии А53Т с повышенной экспрессией $\alpha$-синуклеина не выявил изменений числа В-клеток по сравнению с мышами WT соответствующего возраста. Со- держание в крови $\mathrm{CD} 19^{+} \mathrm{CD} 25^{+} \mathrm{B}-\mathrm{regs}$, определяемое по отношению к числу МНК или Влимфоцитов, у мутантных мышей также оставалось на том же уровне, как и у мышей WT (табл. $3)$.

T а б л и ц а 3. Содержание CD19+ B-клеток и CD19 $^{+}$CD25 $^{+}$B-regs в периферической крови у мышей линий A53T и WT в возрасте 10 месяцев

\begin{tabular}{|l|c|c|}
\hline \multicolumn{1}{|c|}{ Популяции клеток } & Мыши линии WT $(\mathrm{M} \pm \mathrm{m})$ & Мыши линии A53T $(\mathrm{M} \pm \mathrm{m})$ \\
\hline $\mathrm{CD} 19^{+}$B-клеток, \% от МНК & $32,5 \pm 5,9$ & $27,8 \pm 4,3$ \\
\hline $\mathrm{CD} 19^{+} \mathrm{CD} 25^{+} \mathrm{B}-\mathrm{regs}, \%$ от MHК & $9,5 \pm 1,2$ & $10,4 \pm 1,8$ \\
\hline $\mathrm{CD} 19^{+} \mathrm{CD} 25^{+}$B-regs, \% от B-клеток & $31,7 \pm 3,8$ & $38,7 \pm 4,9$ \\
\hline
\end{tabular}

Полученные различия по содержанию B-regs в экспериментальной модели БП и у человека с БП, по-видимому, связаны с тем, что у мышей более значительное накопление $\alpha$-синуклеина и нарушения нейрохимии мозга могут наступать позднее, чем в 10-месячном возрасте.

Хотя нами не обнаружено изменение числа Вклеток при БП, в то же время у женщин отмечалось более высокое, зависимое от стадии, их содержание, чем у мужчин. Из литературы известно, что у $\alpha-$ syn- / - мышей наблюдаются дефекты В-клеточно-опосредованных иммунных реакций [17], а мыши с дефицитом Т-лимфоцитов и Влимфоцитов проявляют устойчивость к МРТРиндуцированной нейродегенерации [18]. Всё вышесказанное указывает на возможность вклада Влимфоцитов в патогенез БП. Что касается субпопуляции $\mathrm{CD}_{19}{ }^{+} \mathrm{CD} 25^{+} \mathrm{B}-$ regs, то, несмотря на предположение об их участии в развитии БП $[8$, 9], сведения об изменении содержания данных клеток при этой патологии в литературе отсутствуют. Нами впервые показано значительное повышение B-regs при прогрессировании заболевания. У пациентов с III стадией БП была выявлена наибольшая разница со здоровыми лицами (контроль). Вероятнее всего, это связано с их включением в регуляцию воспалительных и аутоиммунных процессов, наблюдаемых при БП и, таким образом, в нейропротективные механизмы заболевания. Следует отметить гендерные особенности содержания B-regs в крови пациентов с БП, которое у женщин достоверно различается с таковым у здоровых лиц, в отличие от мужчин. Известно, что пол является одним из факторов риска БП, приводятся данные, что мужчины болеют примерно в 2 раза чаще, чем женщины [19] и, как уже отмечалось [6], высокое содержание Вклеток связано с меньшей тяжестью БП. Выявленные половые различия в содержании В-клеток и B-regs при БП, а также их зависимость от стадии заболевания требуют дальнейшего исследования с привлечением большего количества пациентов, что может стать в будущем основой для разработки новых методов лечения БП.

\section{ЗАКЛЮЧЕНИЕ}

Таким образом, содержание субпопуляции Вклеток $\mathrm{CD} 19^{+} \mathrm{CD} 25^{+}$B-regs в периферической крови при БП значительно превышает их уровень у здоровых лиц, при неизменном количестве самих $\mathrm{CD} 19^{+}$B-клеток. Увеличение B-regs зависит от стадии заболевания, так как оно наиболее выражено у пациентов с III стадией БП. Учитывая, что B-regs подавляют участвующие в воспалении Tx1 и Тх17 и дифференцировку и индукцию Тregs, тормозящих аутоиммунные процессы, можно полагать, что рост их количества говорит об их включении в протективные механизмы развития нейродегенерации и таким образом о тяжести БП.

\section{КОНФЛИКТ ИНТЕРЕСОВ}

Представленные в статье материалы не содержат потенциальных или явных конфликтов интересов авторов.

\section{ИСТОЧНИК ФИНАНСИРОВАНИЯ}

Исследование выполнено при финансовой поддержке РФФИ, проект № 18-015-00226.

\section{СООТВЕТСТВИЕ ПРИНЦИПАМ ЭТИКИ}

В работе применяли клинические и экспериментальные исследования, проведенные с соблюдением принципов гуманности, изложенных в Директивах Европейского Сообщества $(86 / 609 / \mathrm{EC})$, и одобренные Комитетом по биомедицинской этике НИИФФМ (протокол ЛЭК № 3 от 22.03.2018).

$$
\text { ЛИТЕРАТУРA/REFERENCES }
$$

1. Gao H.M., Zhang F., Zhou H., Kam W., Wilson B., Hong J.S. Neuroinflammation and $\alpha$-synuclein dysfunction potentiate each other, driving chronic progression of neurodegeneration in a mouse model of Parkinson's disease. Environ Health Perspect. 2011; 119 (6): 807-881. DOI:10.1289/ehp.1003013

2. Hirsch E.C., Vyas S., Hunot S. Neuroinflammation in Parkinson's disease. Parkinsonism Relat Disord. 2012; 18 Suppl 1:S210-2. doi: 10.1016/S13538020(11)70065-7

3. Williams-Gray C.H., Wijeyekoon R., Yarnall A.J., Lawson R.A., Breen D.P., Evans J.R., Cummins G.A., Duncan G. W., Khoo T.K., Burn D.J., Barker R.A. Serum immune markers and disease progression in an incident Parkinson's disease cohort (ICICLE-PD). Mov Disord. 2016; 31(7):995-1003. doi: $10.1002 / \mathrm{mds} .26563$ 
4. Sulzer D., Alcalay R.N., Garretti F., Cote L., Kanter E., Agin-Liebes J., Liong C., McMurtrey C., Hildebrand W.H., Mao X., Dawson V.L., Dawson T.M., Oseroff C., Pham J., Sidney J., Dillon M.B., Carpenter C., Weiskopf D., Phillips E., Mallal S., Peters B., Frazier A., Lindestam Arlehamn C.S, Sette A. T cells from patients with Parkinson's disease recognize $\alpha$ - synuclein peptides. Nature. 2017; 546: 656661. doi: 10.1038/nature22815

5. Sun C., Zhao Z., Yu W., Mo M., Song C., Youfeng Si Y., Liu Y. Abnormal subpopulations of peripheral blood lymphocytes are involved in Parkinson's disease. Ann Transl Med. 2019; 7(22):637. doi:10.21037/atm.2019.10.105

6. Cen L., Yang C., Huang S., Zhou M., Tang X., Li K., Guo W., Wu Z., Mo M., Xiao Y., Chen X., Yang X., Huang Q., Chen C., Qu S., Xu P. Peripheral Lymphocyte Subsets as a Marker of Parkinson's Disease in a Chinese Population. Neurosci Bull. 2017; 33(5):493-500. doi: 10.1007/s12264-017-0163-9

7. Jiang S., Gao H., Wang P., Luo Q., Yang X. The Correlation of Lymphocyte Subsets, Natural Killer Cell, and Parkinson's Disease: A Meta-Analysis. Neurol Sci. 2017; 38(8):1373-1380. doi: 10.1007/s10072-017-2988-4

8. Sabatino J.J., Pröbstel A-K.,Scott S Zamvil S.S. $\mathrm{B}$ cells in autoimmune and neurodegenerative central nervous system diseases. Nat Rev Neurosci. 2019; 20(12):728-745.doi: 10.1038/s41583-019-0233-2

9. Álvarez-Luquín D.D., Arce-Sillas A., LeyvaHernández J., Sevilla-Reyes E., Boll M.C., MontesMoratillaT., Vivas-Almazán V., Pérez-Correa C., Rodríguez-Ortiz U., Espinoza-CárdenasR., Fragoso G., Sciutto E., Adalid-Peralta L. Regulatory impairment in untreated Parkinson's disease is not restricted to Tregs: other regulatory populations are also involved. J Neuroinflammation. 2019; 16: 212. doi: 10.1186/s12974-019-1606-1

10. Amu S., Gjertsson I., Brisslert M. Functional characterization of murine CD25 expressing B cells. Scand J Immunol. 2010; 71(4):275-82. doi: 10.1111/j.13653083.2010.02380.x

11. Kessel A., Haj T., Peri R., Snir A., Melamed D., Sabo E., Toubi E. Human CD19(+)CD25(high)
B regulatory cells suppress proliferation of CD4(+) T cells and enhance Foxp3 and CTLA-4 expression in T-regulatory cells. Autoimmun Rev. 2012;11 (9):670-677. doi:10.1016/j.autrev.2011.11.018

12. Sakkas L.I., Daoussis D., Mavropoulos A., Liossis S.N., Bogdanos D.P. Regulatory B cells: New players in inflammatory and autoimmune rheumatic diseases. Semin Arthritis Rheum. 2019; 48(6):11331141. doi: 10.1016/j.semarthrit.2018.10.007

13. Rosser E.C., Mauri C. Regulatory B cells: origin, phenotype, and function. Immunity. 2015; 42(4): 07612. doi:10.1016/j.immuni.2015.04.005

14. Wortel C.M., Heidt S. Regulatory B cells: Phenotype, function and role in transplantation. Transpl Immunol. 2017;41:1-9. doi:10.1016/j.trim.2017.02.004

15. Oaks A.W., Frankfurt M., Finkelstein D.I., Sidhu A. Age-dependent effects of A53T alpha-synuclein on behavior and dopaminergic function. PLoS One. 2013; 8(4): e60378. DOI:10.1371/journal.pone.0060378

16. Paumier K.L., Sukoff Rizzo S.J., Berger Z., Chen Y., Gonzales C., Kaftan E., Li L., Lotarski S., Monaghan M., Shen W., Stolyar P., Vasilyev D., Zaleska M., Hirst D., Dunlop W. Behavioral characterization of A53T mice reveals early and late stage deficits related to Parkinson's disease. PLoS One. 2013;8(8):e70274. doi: 10.1371/journal.pone.0070274

17. Xiao W., Shameli A., Harding C.V., Meyerson H.J., Maitta RW. Late stages of hematopoiesis and B cell lymphopoiesis are regulated by $\alpha$-synuclein, a key player in Parkinson's disease. Immunobiology. 2014; 219(11):836-844. doi:10.1016/j.imbio.2014.07.014

18. Benner E.J., Banerjee R., Reynolds A.D. et al. Nitrated alpha-synuclein immunity accelerates degeneration of nigral dopaminergic neurons. PLoS One. 2008; 3(1):e1376. doi:10.1371/journal.pone.0001376

19. Miller I.N., Cronin-Golomb A. Gender differences in Parkinson's diseases. clinical characteristics and cognition. Mov Disord. 2011 Dec 15; 25(6):2695-2701. doi: $10.1002 / \mathrm{mds} .23388$

Поступила в редакцию 29.04.2020 Утверждена к печати 02.09.2020

Жанаева Светлана Яковлевна, к.б.н., в.н.с. сектора психонейроиммунологии НИИФФМ. ㅍㅛㅛ 8-923-225-96-89. zhanaeva@physiol.ru Author ID Scopus 6602352836. ORCID iD 0000-0002-4798-054X. Author ID RSCI 108227.

Альперина Елизавета Лазаревна, д.м.н., г.н.с. сектора психонейроиммунологии НИИФФМ. 푤 8-913-390-0763. lalperina@yahoo.com Author ID Scopus 6603664286. Author ID RSCI 82804.

Геворгян Маргарита Маиловна, к.б.н., с.н.с., сектора психонейроиммунологии НИИФФМ. : 25. gevorgian@btp-nso.ru Author ID Scopus 6507482684. Author ID RSCI 149360.

Дземидович Сергей Сергеевич, врач-невролог НИИФФМ. 푤 8-923-131-11-93. ssdzmidovich@physiol.ru Author ID Scopus 57202588144. ORCID iD 0000-0003-2880-5786. Author ID RSCI 897847.

Идова Галина Вениаминовна, д.б.н., проф., г.н.с. сектора психонейроиммунологии НИИФФМ, профессор кафедры физиологии НГУ. 욜 8-913-933-91-35. galina-idova@mail.ru Author ID Scopus 7004826629.

ORCID iD 0000-0002-9090-514X. Author ID RSCI 82802.

Идова Галина Вениаминовна, galina-idova@mail.ru 
For citation: Zhanaeva S.Ya., Alperina E.L., Gevorgyan M.M., Dzemidovich S.S., Idova G.V. B cells in the peripheral blood in Parkinson's disease. Clinical and experimental data. Siberian Herald of Psychiatry and Addiction Psychiatry. 2020; 3 (108): 11-16. https://doi.org/10.26617/1810-3111-2020-3(108)-11-16

\title{
B cells in the peripheral blood in Parkinson's disease. Clinical and experimental data
}

\section{Zhanaeva S.Ya., Alperina E.L., Gevorgyan M.M., Dzemidovich S.S., Idova G.V.}

State Scientific Research Institute of Physiology and Basic Medicine

Timakov Street 4, 630117, Novosibirsk, Russian Federation

\begin{abstract}
Chronic inflammation is found to play a key role in the pathogenesis of Parkinson's disease that is associated with alterations in the composition of peripheral immunocompetent cells. At present CD $19^{+} \mathrm{B}$ cells, which are known to be involved in adaptive immune responses and the development of multiple CNS disorders, generate a growing interest. However, studies on B cell changes in PD are lacking and produce conflicting results. The aim of the study is to analyze the content of B cells and their subpopulation of $\mathrm{CD} 19^{+} \mathrm{CD} 25^{+} \mathrm{B}$ regulatory cells (B-regs) in the peripheral blood of patients with PD and in transgenic A53T mice with $\alpha$-synucleinopathy. Verification of idiopathic form of PD and its stage is performed according to the UK Parkinson's Disease Society Brain Bank Clinical Diagnostic Criteria and Modified Hoehn and Yahr Scale of disease stages. A53T mice with overexpression of the mutant form of human $\alpha$ synuclein are used as an experimental model of PD with WT mice served as a control. B-lymphocytes and B-regs are determined by flow cytometry using labeled monoclonal antibodies. There are no differences in the blood content of $\mathrm{CD} 19^{+} \mathrm{B}$ cells between the total group of PD patients (men and women) and healthy subjects, while their number in women is higher than in men. The content of $\mathrm{CD} 19^{+} \mathrm{CD} 25^{+}$B-regs is increased in patients in the total group in comparison with healthy subjects and depends on the stage of the disease with the most significant increase found in patients at stage III. In 10-month-old A53T mice, showing PD signs, the number of both CD19 ${ }^{+}$B cells and $\mathrm{CD} 19^{+} \mathrm{CD} 25^{+} \mathrm{B}-$ regs in peripheral blood does not differ from that of WT mice. Thus, our data indicate that while the levels of B cells in PD patients remain unchanged, the content of their subpopulation of B-regs increases with PD progression. It is suggested that B-regs, which produce anti-inflammatory cytokines, are involved in the neuroprotective mechanisms during development of PD.
\end{abstract}

Keywords: Parkinson's disease, mice A53T with $\alpha$-synucleopathy, B cells, B-regulatory cells, peripheral blood.

Received April 29.2020

Accepted September 02.2020

Zhanaeva Svetlana Ya., PhD., lead researcher of Psychoneuroimmunology Department of State Scientific Research Institute of Physiology and Basic Medicine. Author ID Scopus 6602352836. ORCID iD 0000-0002-4798-054X. Author ID RSCI 108227.

Alperina Elizaveta L., MD, chief researcher of Psychoneuroimmunology Department of State Scientific Research Institute of Physiology and Basic Medicine. Author ID Scopus 6603664286. Author ID RSCI 82804.

Gevorgyan Margarita M., PhD., lead researcher of Psychoneuroimmunology Department of State Scientific Research Institute of Physiology and Basic Medicine. Author ID Scopus 6507482684. Author ID RSCI 149360.

Dzemidovich Sergey S., physician neurologist of Psychoneuroimmunology Department of State Scientific Research Institute of Physiology and Basic Medicine. Author ID Scopus 57202588144. ORCID iD 0000-0003-2880-5786. Author ID RSCI 897847.

Idova Galina V., ScD., Prof., chief researcher of Psychoneuroimmunology Department of State Scientific Research Institute of Physiology and Basic Medicine, professor of the Department of Physiology of Novosibirsk State University. Author ID Scopus 7004826629. ORCID iD 0000-0002-9090-514X. Author ID RSCI 82802.

Idova Galina V., galina-idova@mail.ru 